JPPKMI 2 (2) (2021)
JURNAL PENELITIAN DAN PENGEMBANGAN
KESEHATAN MASYARAKAT INDONESIA
JPPKMI

\title{
Perbedaan Pengetahuan dan Sikap Ibu Hamil Sebelum dan Sesudah Menggunakan Media Booklet Tentang Stunting
}

\author{
Amalia Siti Zahra ${ }^{1} \bowtie$, Sinta Fitriani ${ }^{1}$, Dadan Yogaswara ${ }^{1}$ \\ ${ }^{1}$ Program Studi S1 Kesehatan Masyarakat, STIKes Respati, Indonesia
}

\begin{tabular}{l}
\hline Info Artikel \\
\hline Sejarah Artikel: \\
Diterima Juni 2021 \\
Disetujui Desember 2021 \\
Dipublikasi Desember 2021 \\
\hline Keywords: \\
Booklet, Stunting, Pregnant \\
Women, Knowledge, Attitude \\
\hline URL: \\
https://iournal.unnes.ac.i \\
$\frac{\text { d/siu/index.php/ippkmi }}{\text { /article/view/52427 }}$ \\
\hline
\end{tabular}

\begin{abstract}
Abstrak
Stunting adalah kondisi gagal tumbuh pada anak balita (bayi di bawah lima tahun) akibat dari kekurangan gizi kronis sehingga anak terlalu pendek untuk usianya.Salah satu faktor yang behubungan dengan kejadian stunting dipengaruhi oleh pengetahuan dan sikap ibu. Tujuan Penelitan ini adalah Mengetahui Perbedaan Pengetahuan dan Sikap Ibu Hamil Sebelum Dan Sesudah Menggunakan Media Booklet tentang Stunting di Desa Cikunir Kecamatan Singaparna Kabupaten Tasikmalaya Tahun 2021. Jenis penelitian yang di gunakan adalah kuantitatif metode analitik dengan design Eksperimen semu (Quasi Eksperimen). Pendekatan yang digunakan dalam penelitian ini One Group Pretest - Postest uji yang digunakan adalaha Uji T-Dependent. Populasi dan sampel dalam penelitian adalah seluruh ibu hamil yang berada di Desa cikunir. Teknik pengambilan sampel yaitu purposive sampling sebanyak 50 orang ibu hamil. Instrumen yang digunakan adalah kuesioner dan booklet. Tehnik analisis data menggunakan uji $t$. Hasil penelitian menunjukan nilai $\mathrm{p}$ value sebesar $0.002<\mathrm{a}(0.05)$ artinya terdapat perbedaan yang signifikan rata - rata nilai pengetahuan ibu hamil sebelum dan sesudah diberikan media Booklet tentang Stunting sedangkan Hasil uji statistik variabel sikap p value $0.015>$ a $(0.05)$ artinya terdapat perbedaan yang signifikan rata - rata nilai sikap ibu hamil sebelum dan sesudah diberikan media Booklet. Ibu hamil diharapkan dapat meningkatkan pengetahuannya serta menanamkan sikap postif agar dapat melakukan perilaku pencegahan Stunting melalui kegiatan peningkatan pencarian informasi kesehatan melalui kegiatan seminar kesehatan, penyuluhan di posyandu serta memanfaatkan media promosi kesehatan.
\end{abstract}

\begin{abstract}
Stunting is a condition of failure to thrive in children under five years of age as a result of chronic malnutrition so that children are too short for their age. One of the factors related to the incidence of stunting is influenced by the mother's knowledge and attitude. The aim of this research is Knowing the Differences in Knowledge and Attitudes of Pregnant Women Before and After Using Media Booklets about Stunting in Cikunir Village, Singaparna District, Tasikmalaya Regency in 2021. The type of research used is quantitative analytical method with quasi-experimental design (Quasi Experiment). The approach used in this study is One Group Pretest - Posttest, the test used is the T- Dependent Test. The population and sample in this study were all pregnant women in Cikunir Village. The sampling technique was purposive sampling as many as 50 pregnant women. The instruments used are questionnaires and booklets. Data analysis technique using t test. The results showed that the p value was $0.002<(0.05)$ meaning that there was a significant difference in the average value of knowledge of pregnant women before and after being givenmedia Booklet about Stunting, while the results of the statistical test of the attitude variable $p$ value $0.015>$ (0.05) meaning that there was a difference. which is significant the average value of the attitude of pregnant women before and after being givenmedia Booklet. Pregnant women are expected to increase their knowledge and instill a positive attitude in order to carry outprevention behavior stunting through activities to increase the search for health information through health seminars, counseling at posyandu and utilizing health promotion media.
\end{abstract}

Alamat korespondensi:

Universitas Respati, Indonesia

E-mail: amaliazahra2701@gmail.com 


\section{PENDAHULUAN}

Balita pendek (stunted) dan sangat pendek (severely stunted) adalah balita dengan panjang badan $(\mathrm{PB} / \mathrm{U})$ atau tinggi badan $(\mathrm{TB} / \mathrm{U})$ menurut umurnya dibandingkan dengan standar baku WHO-MGRS (Multicentre Growth Reference Study) 2006. Sedangkan definisi Stunting menurut Kementerian Kesehatan (Kemenkes) adalah anak balita dengan nilai z-skor nya kurang dari $-2 \mathrm{SD} /$ standar deviasi (stunted) dan kurang dari - 3 SD (severely stunted). (TNP2K, 2017: 5).

Berdasarkan Data WHO, Indonesia termasuk ke dalam negara ketiga dengan prevalensi tertinggi di Regional Asia dengan rata - rata prevalensi balita Stunting di Indonesia tahun 2005 - 2017 adalah 36,4 \%. Pada tahun 2017 Prevalensi Stunting terdapat 22,2 \% atau sekitar 150,8 juta balita di dunia mengalami Stunting. Di Indonesia Kejadian Stunting menurut data Riset Kesehatan Dasar (Riskesdas) Kementerian Kesehatan, angka stunting nasional mengalami penurunan dari $37,2 \%$ pada 2013 menjadi 30,8\% pada 2018 . Menurut Survei Status Gizi Balita Indonesia (SGBI) pada 2019, angka ini menurun menjadi $27,7 \%$. Penurunan angka stunting telah dinyatakan sebagai program prioritas nasional

Berdasarkan data dari Dinas Kesehatan Kabupaten Tasikmalaya didapatkan bahwa kejadian stunting pada tahun 2013 yaitu 41.7\% dan mengalami penurunan pada tahun 2018 yaitu $33.8 \%$. Kecamatan Singaparna menjadi salah satu lokasi khusus yang ditetapkan oleh Bupati Tasikmalaya dengan prevalensi stunting pada tahun 2020 adalah 5,2\%. Salah satu Desa di Kecamatan Singaparna adalah Desa Cikunir berdasarkan laporan PPGBM Dinas Kesehatan Kabupaten pada bulan Februari tahun 2021 didapatkan data 69 dari 357 bayi balita usia 0 59 bulan (19,3 \%) memiliki tinggi badan tidak sesuai dengan umurnya. Selain itu penelitian yang dilakukan oleh Chanty Yuni tahun 2021 didapatkan data bahwa perilaku gizi pada ibu hamil masih kurang seperti : ibu hamil pantangan makan ikan saat hamil sebanyak 11,5 $\%$ persen, persepsi keliru tentang ikan laut tidak dapat membantu Pertumbuhan Janin sebanyak $20,7 \%$ persen serta cara konsumsi tablet $\mathrm{Fe}$ yang salah sehingga berpotensi menimbulkan anemia pada ibu hamil sebanyak 33,3\%.

Untuk mencegah risiko stunting, diperlukan upaya pencegahan melalui upaya peningkatan perilaku yang sehat seperti pemenuhan kebutuhan gizi dan perilaku kesehatan lingkungan. Perilaku perlu dilakukan semenjak masa kehamilan, karena salah satu faktor gizi pada masa kehamilan seperti Kekurangan Energi Kronik dan anemia menjadi salah satu penyebab risiko stunting. Sehingga edukasi kesehatan sangat diperlukan oleh ibu hamil melalui beberapa kegiatan seperti menghadiri penyuluhan di posyandu atau memanfaatkan media massa serta media sosial lainnya.

Sikap dan Perilaku yang positif dapat dibentuk dari pengetahuan yang baik, sehingga cara yang tepat untuk meningkatkan pengetahuan adalah dengan menggunakan media sebagai pendidikan kesehatan. Salah satu pendukung proses penangkapan informasi adalah adanya media pembelajaran, media promosi kesehatan yang dapat meningkatkan pengetahuan salah satunya adalah Booklet.Booklet merupakan salah satu media promosi kesehatan dalam bentuk inovasi media pembelajaran dalam bentuk media cetak. Media ini memuat materi pelajaran dalam bentuk fisik yang unik, menarik, dan fleksibel.. tujuan dari penelitian ini adalah mengetahui perbedaan pengetahuan dan sikap ibu hamil sebelum dan sesudah di berikan media booklet tentang stunting.

\section{METODE}

Desain penelitian ini adalah Quasi Eksperimen dengan memberikan perlakuan yaitu memberikan pre test pada saat sebelum membaca booklet, memberikan booklet pada ibu hamil untuk dibaca dan dipahami, seteah itu diberikan postets dengan soal yang sama.

Intervensi ini dilakukan untuk mnegetahui perbedaan pengetahuan dan sikap ibu hamil sebelum dan sesudah mengunakan 
media booklet tentang stunting kepada ibu hamil di desa cikunir kecamatan singaparna kabupaten tasikmlaya.

Penelitian inimneggunakan data primer, yang dilakukan pada bulan juni tahun 2021 . Analisis dilakukan dengan menggunakan Uji $\mathrm{T}$ untuk melihat perbedaan pengetahuan dan sikap ibu hamil sebelum dan sesudah menggunakan media booklet . Tingkat kepercayaan yang digunakan (CI) $95 \%(\alpha=$ $0,05)$.

\section{HASIL DAN PEMBAHASAN}

Hasil penelitian di daatkan bahwa setelah diberikan intervensi penyuluhan dengan media booklet terdapat peningkatan pengetahuan signifikan secara statistik.

Hasil uji statistik didapatkan nilai $\mathrm{p}$ value sebesar 0.015 dan jika dibandingkan dengan nilai $\mathrm{a}=0.05, \mathrm{p}$ value $\geq \mathrm{a}$ artinya terdapat perbedaan yang signifikan rata - rata nilai sikap ibu hamil sebelum dan sesudah diberikan media Booklet tentang Stunting di Desa Cikunir Kecamatan Singaparna.

\section{Pengetahuan ibu hamil}

Berdasarkan hasil analisis didapatkan hasil bahwa Rata - rata nilai pengetahuan ibu hamil tentang Stunting sebelum diberikan media Booklet yaitu 5.38 dengan standar deviasi 1.640, serta nilai terendah adalah 2 dan nilai tertinggi 8. Sedangkan rata - rata nilai pengetahuan ibu hamil tentang Stunting sesudah diberikan media Booklet yaitu 6.26 dengan standar deviasi 1.121, serta nilai terendah adalah 4 dan nilai tertinggi 8.

$\begin{array}{rcc}\text { Notoatmodjo menuturkan } & \text { bahwa } \\ \text { perilaku terbentuk didasari oleh } & \text { sebuah }\end{array}$

pengetahuan. Begitu pula dengan perilaku pencegahan Stunting pada masa kehamilan harus didukung oleh pengetahuan ibu hamil. Ibu hamil perlu mengetahui upaya yang dilakukan semasa kehamilan agar tercegah dari kejadian Stunting seperti definisi Stunting, faktor penyebab Stunting, dampak Stunting, pencegahan Stunting, kebutuhan gizi ibu hamil dan status gizi ibu Hamil.

Hal ini sesuai dengan hasil penelitian yang dilakukan oleh Asri Masitha Arsyati di Cibungbulang tahun 2019 yang menyatakan bahwa ibu hamil yang melakukan upaya pencegahan Stunting mayoritas dilakukan oleh ibu hamil yang memiliki pengetahuan baik yaitu 78.6\%. Hal ini juga didukung oleh penelitian yang dilakukan oleh Wulandari dkk di Wilayah Kerja Puskesmas Ulak Muid Kabupaten Melawi pada tahun 2016 menyatakan bahwa ibu dengan pengetahuan yang kurang baik mempunyai risiko sebesar 1,644 kali memiliki balita Stunting jika dibandingkan dengan ibu yang mempunyai pengetahuan baik.

\section{Sikap Ibu Hamil}

Pada penelitian ini hasil rata - rata nilai Sikap ibu hamil tentang Stunting sebelum diberikan media Booklet yaitu 6.66 dengan standar deviasi 1.560 , serta nilai terendah adalah 2 dan nilai tertinggi 9 . Sedangkan hasil rata - rata nilai Sikap ibu hamil setelah diberikan media Booklet yaitu 7.28 dengan standar deviasi 1.443 , serta nilai terendah adalah 3 dan nilai tertinggi 9 .

Sikap merupakan suatu reaksi atau respon yang masih tertutup dari seseorang terhadap suatu stimulus atau objek, manifestasi sikap itu tidak dapat langsung dilihat tetapi hanya dapat menafsirkan terlebih

Tabel 1. Hasil Uji Perbedaan Pengetahuan Ibu Hamil di Desa Cikunir Kecamatan Singaparna

\begin{tabular}{llllll}
\hline Pengetahuan & Mean & SD & SE & P Value & N \\
\hline Sebelum & 5.38 & 1.640 & 0.232 & \multirow{2}{*}{0.002} & 50 \\
Sesudah & 6.26 & 1.121 & 0.159 & & \\
\hline
\end{tabular}

Tabel 2. Hasil Uji Perbedaan sikap Ibu Hamil di Desa Cikunir Kecamatan Singaparna

\begin{tabular}{llllll}
\hline Sikap & Mean & SD & SE & P Value & N \\
\hline Sebelum & 6.66 & 1.560 & 0.221 & \multirow{2}{*}{0.015} & \multirow{2}{*}{50} \\
Sesudah & 7.28 & 1.443 & 0.204 & & \\
\hline
\end{tabular}


dahulu dari perilaku yang tertutup, sikap secara nyata menunjukkan konotasi adanya kesesuaian reaksi terhadap stimulus tertentu yang dalam kehidupan sehari-hari merupakan reaksi yang bersifat emosional terhadap stimulus sosial (Notoatmodjo, 2014). Salah satu domain perilaku adalah sikap, sikap positif sangat dibutuhkan agar ibu hamil dapat melakukan perilaku pencegahan Stunting pada masa kehamilan. Contoh perilaku pencegahan yang dapat dilakukan oleh ibu hamil dalam upaya pencegahan Stunting ialah mengkonsumsi tablet $\mathrm{FE}$, melakukan pemeriksaan kandungan rutin ke posyandu dan mengkonsumsi makanan dengan gizi seimbang.

Hal ini sesuai dengan hasil penelitian Sri Arnita,dkk tahun 2020 di Wilayah Kerja Puskesmas Simpang Kawat Kota Jambi tahun 2020 yang menyatakan bahwa Ada hubungan yang signifikan antara sikap ibu dengan upaya pencegahan Stunting dimana $p$-value $=0,030$ $(p<0,05)$.

\section{Pengaruh Pemberian Media Promosi Kesehatan Booklet Terhadap Pengetahuan dan Sikap ibu hamil tentang stunting}

Hasil uji statistik didapatkan pada variabel pengetahuan nilai $p$ value sebesar 0.002 dan pada variabel sikap didapatkan nilai $p$ value sebesar 0.015 jika dibandingkan dengan nilai a $=0.05$ Artinya terdapat perbedaan yang signifikan rata - rata pengetahuan dan sikap ibu hamil sebelum dan sesudah diberikan media Booklet tentang Stunting di Desa Cikunir Kecamatan Singaparna Kabupaten Tasikmalaya Tahun 2021. Hal ini sesuai dengan teori dimana Media merupakan sarana untuk menyampaikan pesan kepada sasaran sehingga mudah dimengerti oleh sasaran yang dituju adapun media promosi kesehatan adalah upaya untuk menyampaikan pesan atau informasi yang ingin disampaikan oleh komunikator baik itu melalui media cetak, elektronik maupun media luar ruang sehingga sasaran dapat meningkatkan pengetahuannya yang akhirnya diharapkan dapat berubah perilakunya ke arah positif terhadap kesehatannya.

Hasil penelitian ini didukung dengan penelitian dilakukan oleh Anita Dyah Listyarini dan Yayuk Fatmawati yang berjudul Edukasi Gizi Ibu Hamil Dengan Media Booklet Tentang Perilaku Pencegahan Balita Stunting Di Wilayah Puskesmas Undaan Kabupaten Kudus menyatakan bahwa Hasil penelitian menunjukan dari hasil analisa Uji Paired t test diketahui perbedaan pretest dan posttest Edukasi gizi menggunakan media Booklet adalah nilai $\mathrm{p}=$ $0,000<\alpha 0,05$. Dengan demikian Ho ditolak yang berarti ada Pengaruh edukasi gizi ibu hamil menggunakan media Booklet terhadap perilaku pencegahan Stunting di wilayah kerja Puskesmas Undaan Kabupaten Kudus. Adapun Penelitian yang dilakukan oleh Tyas Dwi Puspita di Desa Grogol Kecamatan Weru pada tahun 2017 menyebutkan bahwa nilai pengetahuan responden sebelum 54,8\% termasuk kategori baik kemudian mengalami peningkatan menjadi $85,7 \%$ responden memiliki pengetahuan baik setelah mengikuti penyuluhan dengan menggunakan media Booklet. Untuk variabel sikap diketahui bahwa jumlah responden yang memiliki sikap positif sebelum intervensi adalah 54,8\% dan mengalami peningkatan menjadi 100 persen setelah mengikuti penyuluhan dengan media Booklet. Serta Hasil uji beda pada variabel pengetahuan terdapat pengaruh $(\mathrm{p}=0,002)$. Variabel sikap terdapat pengaruh $(p=0,000)$. Kesimpulan dari penelitian adalah adanya pengaruh penyuluhan dengan media Booklet terhadap pengetahuan dan sikap ibu anak balita di desa Grogol, kecamatan Weru, kabupaten Sukoharjo.

\section{PENUTUP}

Dari penelitian ini didapatkan bahwa adanya perbedaan pengetahuan dan sikap ibu hamil sbelum dan sesudah di berikan intervensi penyuluhan dengan media booklet tentang stuning di desa cikunir kecamatan singarparna kabupaten tasikmalaya tahun 2021. Ibu Hamil dapat meningkatkan pengetahuannya serta menanamkan sikap positif agar dapat melakukan perilaku pencegahan Stunting melalui kegiatan peningkatan pencarian informasi kesehatan melalui kegiatan seminar 
kesehatan, penyuluhan di posyandu serta memanfaatkan media promosi kesehatan seperti media Booklet yang telah peneliti rancang.

Para promotor kesehatan dapat Merancang kegiatan edukasi kesehatan dengan mengacu pada hasil analisis situasi masyarakat sehingga kegiatan edukasi kesehatan sesuai dengan kebutuhan masyarakat,selain itu petugas promkes dapat memanfaatkan media Booklet tentang Stunting yang telah Peneliti rancang sebagai media edukasi kesehatan kepada masyarakat khususnya ibu hamil.

\section{DAFTAR PUSTAKA}

Ahmad Kholid(Apu et al., 2015). 2014. Promosi Kesehatan

Andreansyah. 2015 . Oktober, 13 2015. Pengembangan Booklet Sebagai Media Pembelajaran Geografi Pada Materi Dinamika Litosfer Dan Pengaruhnya Terhadap Kehidupan Di Muka Bumi Kelas X Di Sma Negeri 12 Semarang Tahun 2015. Jurusan Geografi Fakultas Ilmu Sosial Universitas Negeri Semarang. http://lib.unnes.ac.id/27262/1/3201411049. pdf

Anita R dan Nurmawati T, Liliani p. 2019. Faktor yang Berhubungan dengan Pengetahuan Orang tua tentang Stunting pada Balita. Jurnal Ners Dan Kebidanan. 6: 389-395. file:///C:/Users/ASUS/AppData/Local/Te mp/500-2224-3-PB.pdf

Anita, D.L., Fatmawatia, Y. 2020. Edukasi Gizi Ibu Hamil Dengan Media Booklet Tentang Perilaku Pencegahan Balita Stunting Di Wilayah Puskesmas Undaan Kabupaten Kudus. Jurnal Ilmu Keperawatan dan Kebidanan, 11(1): 100-105

Arnita,S.,Rahmadhani,D.Y.,Sari,T.M,. 2020. Hubungan Pengetahuan dan Sikap Ibu dengan Upaya Pencegahan Stunting pada Balita di Wilayah Kerja Puskesmas Simpang Kawat Kota Jambi. http://jab.stikba.ac.id/index.php/jab/article/vie $w / 149$

Azwar, S. 2011. Sikap dan Perilaku Dalam: Sikap Manusia Teori dan Pengukurannya. Yogyakarta: Pustaka Pelajar.

Badan Perencanaan dan Pembangunan Nasional. 2018. Pedoman Pelaksanaan Intervensi Penurunan Stunting Terintegrasi di Kabupaten/
Kota. Jakarta: Kementerian Perencanaan Pembangunan Nasional.

Chrisyanti Dewi, Irra. 2015. Pengantar Psikologi Media, Jakarta : Prestasi Pustaka Publisher

Fitriani, Sinta. 2019. Pemodelan Desa Tanggap Stunting Melalui Pemberdayaan Masyarakat Di Desa Cikunir Kecamatan Singaparna Kabupaten Tasikmalaya Tahun 2019. Tasikmalaya. Vol 2 No 01 (2020): Prosiding Seminar Nasional Kesehatan "Peran Tenaga Kesehatan Dalam Menurunkan Kejadian Stunting dalam http://ejurnal.stikesrespatitsm.ac.id/index.php/semnas/issue/view/33. Diakses 26 April 2020.

Fitriani, Sinta. 2011. Promosi Kesehatan. Yogyakarta .Garaha Ilmu.

Hartiningrum, Yunie Chanty. 2021. Persepsi Ibu Hamil Tentang Gizi Yang Beresiko Menimbulkan Stunting Di Desa Cikunir Singaparna Kabupaten Tasikmalaya Tahun 2020

Harikatang, M.R., etal. 2020. Hubungan Pengetahuan Dan Sikap Ibu Dengan Kejadian Balita Stunting Di Satu Kelurahan Di Tangerang. 3(2)

Jalal, Fasil. 2017. Penanggulangan Stunting dan Peningkatan Mutu Pendidikan Sebagai Contoh Upaya Pencapaian Tujuan SDGs. Jakarta.

Kementrian Desa, Pembangungan Daerah Tertinggal dan Transmigrasi. 2017. Buku Saku dalam Penanganan Stunting. Kementrian Desa, Pembangungan Daerah Tertinggal dan Transmigrasi.

Kementerian Koordinator Bidang Pembangunan Manusia dan Kebudayaan. 2018. Strategi Nasional Percepatan Pencegahan Anak Kerdil (Stunting) Periode 2018-2024. Jakarta: Sekretariat Wakil Presiden Republik Indonesia.

Khatimah, Husnul. 2018. Posisi Dan Peran Media Dalam Kehidupan Masyarakat. 16(1): 199 file:///C:/Users/ASUS/AppData/Local/Te $\mathrm{mp} / 548$-Article\%20Text-873-1-1020190123.pdf

Kumboyono. 2011. Perbedaan Efek Penyuluhan Kesehatan Menggunakan Media Cetak dengan Media Audiovisual terhadap Peningkatan Pengetahuan Pasien Tuberkulosis. Malang: Jurnal Ilmiah Kesehatan Keperawatan, 5(3) Fakultas Kesehatan Universitas Brawijaya. 
Kusumawati, Erna et al. 2015. Model Pengendalian Faktor Risiko Stunting pada Anak Usia di Bawah Tiga Tahun. Jurnal Kesehatan Masyarakat Nasional, 9(3), Februari 2015.

Laporan Hasil BPB Kab. Tasikmalaya, 2016, 2017, 2018

Ma'munah, Malikatul. 2015.Pengaruh Pendidikan Kesehatan Dengan Booklet Terhadap Pengetahuan Nutrisi Ibu Laktasi Di Wilayah Kerja Puskesmas Ciputat Timur. October 2015, Universitas Islam Negeri Syarif Hidayatullah Jakarta, Program Studi Ilmu Keperawatan. http://repository.uinjkt.ac.id/dspace/bitstrea m/123456789/38022/1/MALIKATUL\%20 MA\%27MUNAH-FKIK.pdf

Masitha, A. 2019. Promotor pengaruh penyuluhan media Audiovisual Dalam Pengetahuan Pencegahan Stunting pada Ibu Hamil di Desa Cibatok 2 cibungbulangasri. Promotor Jurnal Mahasiswa Kesehatan Masyarakat . 2(3), Juni. http://ejournal.uika-bogor.ac.id/index.php/

Meike, Naria Doneatella. 2017. Efektivitas Media Booklet tentang Dampak Pornografi Terhadap Pengetahuan Dan Sikap Siswa-Siswi Di Sma Santun Untan Pontianak 2017. Pontianak. Dalam http://repository.unmuhpnk.ac.id/578/1/Co ver.pdf. Diakses 26 april 2020.

Nasrulloh, Rulli. 2016. Teori dan Riset Media (Cybermedia). Jakarta. Prenadamedia Group.

Notoatmodjo, Soekidjo. 2010. Metodologi Penelitian Kesehatan. Jakarta: Rineka cipta

Notoatmodjo, S. 2014. Promosi Kesehatan dan Perilaku Kesehatan. Jakarta: Rineka Cipta.

Olsa, E.D,. Sulastri, D., \& Ana, E. 2017. Hubungan Sikap dan Pengetahuan Ibu Terhadap Kejadian Stunting pada Anak Baru Masuk Sekolah Dasar di Kecamanatan Nanggalo. Jurnal Fakultas Kedokteran. http://jurnal.fk.unand.ac.id/index.php/jka/a rticle/view/733

Pusat Data dan Informasi Kementerian Kesehatan RI

Pusat Data dan Informasi. 2018. Situasi Balita Pendek (Stunting) di Indonesia. Jakarta: Kemenkes RI

Roza, S. 2012. Media Gizi Booklet. Padang. Poltekes kemenkes RI Padang
Siregar, P.A. etal. 2020. Promosi Kesehatan Lanjutan Dalam Teori Dan Aplikasi. Jakarta. Prenadamedia Group

Saputri, R.A. 2019. Upaya Pemerintah Daerah Dalam Penanggulangan Stunting Di Provinsi Kepulauan Bangka Belitung. Jurnal Dinamika Pemerintahan, 2(2): 152-168 152

Sukmawati, etal. 2018. Status Gizi, Ibu Hamil 18 Status Gizi Ibu Saat Hamil, Berat Badan Lahir Bayi Dengan Stunting Pada Balita. Media Gizi Pangan, 25(1), 2018

Sunarya, Lusyani. 2015. Keefektifan Media Komunikasi Visual Sebagaipenunjang Promosi Pada Perguruan Tinggi Raharja. Universitas Islam Syekh Yusuf Tangerang. Manajemen Informatika. https://media.neliti.com/media/publications /296345-keefektifan-media-komunikasivisual-seba-ce941b12.pdf

Susilowati, Dwi. 2016. Promosi Kesehatan. Jakarta Pusdik SDM Kesehatan Kemenker RI..

Sutopo, agus. et al.,. 2014. Kajian Indikator Sustainable Development Goals (SDGs). Jakarta: Badan Pusat Statistik

Tyas Dwipuspita Hati. 2017. Agustus 07,2017. Program Studi Ilmu Gizi fakultas Ilmu Kesehatan universitas Muhammadiyah Surakarta.

http://eprints.ums.ac.id/56578/1/PUBLIKA SI\%20KARYA\%20ILMIAH.

Tim Nasional Percepatan Penanggulangan Kemiskinan. 2017. 100 Kabupaten/Kota Prioritas Untuk Intervensi Anak Kerdil (Stunting). Jakarta: Sekretariat Wakil Presiden Republik Indonesia. Pdf

Warsini, T.K., Hadi, H.,\& Nurdiat, D.S. 2016. Riwayat KEK dan anemia pada ibu hamil tidak berhubungan dengan kejadian Stunting pada anak usia 6-23 bulan di Kecamatan Sedayu. Jurnal Gizi Dan Dietetik Indonesia, 4(1), Januari 2016: 29-40

Yessie Finandita Pratiwi1, Dyah Intan Puspitasari2 . 2017. Efektivitas Penggunaan Media Booklet Terhadap Pengetahuan Gizi Seimbang Pada Ibu Balita Gizi Kurang Di Kelurahan Semanggi Kecamatan Pasar Kliwon Kota Surakarta. Surakarta . Jurnal Kesehatan, ISSN 19797621, 10(1) 